\title{
ESTUDO SOBRE A INFLUÊNCIA DE VARIÁVEIS METEREOLÓGICAS NOS CASOS DE ACIDENTES POR ANIMAIS PEÇONHENTOS EM LAGES - SC
}

\section{STUDY ON THE INFLUENCE OF METEOROLOGICAL VARIABLES IN THE CASES OF ATTACKS BY PESTS IN LAGES - SC}

\author{
Daiane Teixeira Schier \\ Discente do Programa de Pós-Graduação em Ciências Ambientais \\ Universidade do Estado de Santa Catarina/UDESC \\ daiane schier@hotmail.com \\ Mayara Rafaeli Lemos \\ Discente do Programa de Pós-Graduação em Ciências Ambientais \\ Universidade do Estado de Santa Catarina/UDESC \\ may rafaeli@hotmail.com \\ Claudia Guimarães Camargo Campos \\ Docente do Programa de Pós-Graduação em Ciências Ambientais \\ Universidade do Estado de Santa Catarina/UDESC \\ claudia.campos@udesc.br \\ Josiane Teresinha Cardoso \\ Docente do curso de Engenharia Ambiental e Sanitária \\ Universidade do Estado de Santa Catarina/UDESC \\ josiane.cardoso@udesc.br
}

\begin{abstract}
RESUMO
A incidência de acidentes por animais peçonhentos se constitui como a segunda causa de notificação epidemiológica no Brasil. Em 2016, do total de casos notificados, $16 \%$ correspondem à região sul. Sendo assim, com o objetivo de analisar a possível relação entre os fatores meteorológicos e os casos de notificação de acidentes por animais peçonhentos no município de Lages-SC entre os anos de 2011 a 2017, buscou-se dados a respeito do número de notificações, além de informações sobre a precipitação e temperatura do ar para o período de interesse. As informações relativas aos casos de acidentes por animais peçonhentos foram obtidas pelos indicadores compulsórios do SINAN, enquanto que os dados meteorológicos foram fornecidos pela EPAGRI/CIRAM. O coeficiente de correlação de Pearson foi calculado utilizando-se o software Excel, em que se verificou que os acidentes por animais peçonhentos apresentaram correlação com a temperatura do ar para todos os anos de estudo, sendo o coeficiente mais alto obtido para $o$ ano de $2013(r=0,75)$. Além disso, os casos possuem maiores frequências para janeiro, sente este 0 mês com temperatura média do ar mais elevada. Dessa forma, torna-se evidente que medidas de cunho preventivo necessitam ser tomadas para diminuir os registros de acidentes por animais peçonhentos, principalmente nos meses de temperaturas mais altas, em que a população possui maior risco de contato com os mesmos e, portanto, deve ser alertada para tomar maiores precauções neste período.
\end{abstract}

Palavras-chave: Animais venenosos. Precipitação.Temperatura.

\section{ABSTRACT}

The incidence of accidents by venomous animals constitutes the second cause of epidemiological notification in Brazil. In 2016, of the total reported cases, $16 \%$ corresponded to the southern region. Thus, with the objective of analyzing the possible relationship

Recebido em: 10/12/2018

Aceito para publicação em: 01/04/2019 
between meteorological factors and cases of notification of accidents by venomous animals in the municipality of Lages-SC between the years 2011 to 2017, data were sought regarding the number of notifications, in addition to information on precipitation and air temperature for the period of interest. Information on cases of accidents involving venomous animals was obtained by the SINAN compulsory indicators, while the meteorological data were provided by EPAGRI/CIRAM. The Pearson correlation coefficient was calculated using the Excel software, where it was verified that the accidents by venomous animals showed correlation with the air temperature for all the years of study, being the highest coefficient obtained for the year $2013(r=0.75)$. In addition, the cases have larger records in January, being the month with high values of total precipitation and average air temperature. In view of the significant number of reports of accidents by venomous animals, it is evident that preventive measures need to be taken to reduce such records, especially in the months of expressive temperatures in which the population has a higher risk of contact with venomous animals, should be warned to take more precautions during this time.

Keywords: Venomous animals. Precipitation Temperature.

\section{INTRODUÇÃO}

A recorrência de acidentes por animais peçonhentos em regiões de clima tropical levou a Organização Mundial da Saúde (OMS) a incluí-los na lista de doenças Tropicais Negligenciadas. Os casos possuem impacto importante nos países do continente africano, asiático e América Latina, sendo o Brasil o país com maior número absoluto neste último grupo (BERALDO et al., 2017).

Acidentes envolvendo os animais peçonhentos se constituem como a segunda causa de notificação epidemiológica no Brasil (MESCHIAL et al., 2017). Em 2015 foram documentados um total de 150.000 acidentes por animais peçonhentos, já em 2016, o número passou para 172.412 casos, dos quais 27.590 ocorreram na região sul do Brasil, o que equivale a $16 \%$ das intoxicações notificadas no país (MINISTÉRIO DA SAÚDE, 2018).

No estado de Santa Catarina, segundo dados do Centros De Informações e Assistência Toxicológica (CIATox/SC), em 2016 teve-se um total de 3.245 notificações de acidentes envolvendo os animais peçonhentos, sendo a maior parte destes ocasionado por aranhas (1.679), lagartas (650), serpentes (584) e escorpiões (200) (CIATox/SC, 2019).

Os problemas relacionados à saúde da população são acentuados devido a determinados fatores, entre eles, as condições sociais de cada região e os elementos meteorológicos, que podem intensificar as atividades de animais específicos, levando a agravos notificáveis que respondem em algumas situações climáticas específicas (SANTOS; FILHO, 2014).

Apesar dos números alarmantes de notificações de acidentes por animais peçonhentos retratarem um agravante na saúde pública, a base de dados epidemiológicos no Brasil ainda é insubsistente, havendo falhas na documentação dos casos e lapsos de informações. Dessa forma, nem todas as ocorrências de acidentes são inseridas nas estatísticas oficiais do Ministério da Saúde (MESCHIAL et al., 2013).

Os animais peçonhentos estão presentes em diversos tipos de ambientes e apesar de não serem determinados com clareza os fatores que acarretam mudanças no padrão de suas populações, o desequilíbrio ecológico ocasionado pelo desmatamento e a expansão de núcleos urbanos ocorrida ao longo dos anos, predispõem o ser humano ao risco de acidente devido a maior exposição homem-animal (SANTANA; BARROS; SUCHARA, 2016).

As causas dos acidentes podem ser consideradas como multifatoriais, as mesmas estão ligadas a alguns aspectos, como as características meteorológicas de cada região, redução do seu habitat natural e a realização de atividades agrícolas nas zonas rurais (BERALDO et al., 2017).

Em eventos de cheia, alguns animais peçonhentos buscam ambientes secos para se abrigarem, adentrando em residências, o que acarreta no aumento do risco de acidentes 
causados por esses animais, principalmente em épocas de maiores precipitações, merecendo atenção especial pela população (LEOBAS; FEITOSA; SEIBERT, 2016).

Atrelado a isso, nos meses correspondentes ao período de verão se tem maior ocorrência de acidentes, pois diferente dos mamíferos, esses animais não regulam sua temperatura e, por isso, buscam locais de maior exposição ao sol. Além disso, é a época em que os animais possuem maior atividade, buscando alimentos e parceiros para a reprodução, tornando-os mais expostos e, portanto, acentuando o risco de acidentes (MINISTÉRIO DA SAÚDE, 2017).

O contato com os animais peçonhentos pode ocorrer através de mordidas, picadas, ferroadas, arranhões, contato com a pele ou ainda pela ingestão do animal peçonhento pela vítima. Dessa forma, os acidentes provocados por esses animais são considerados um problema de saúde pública no Brasil, em virtude do elevado número de pessoas envolvidas anualmente e também pelas gravidade e complicações que podem apresentar (DIVE, 2018).

Estudos desenvolvidos no estado do Paraná e São Paulo demonstram que o registro de acidentes apresenta relação direta com a temperatura média do ar. Nos meses correspondentes ao período de verão, em que se tem uma associação de temperaturas elevadas e maiores índices pluviométricos, há um favorecimento no aumento do número de casos devido a intensificação e a frequência com que os animais peçonhentos apresentam atividade (HAAS et al., 2013; SOUZA; NASCIMENTO, 2017). Sendo assim, a temperatura do ar elevada possibilita maior atividade em diversas espécies de aranhas, escorpiões e serpentes, contribuindo para que o número de acidentes provocados por esses animais ocorra com maior frequência nos meses de altas temperaturas (SANTOS; TORNQUIST; MARIMON, 2014).

Diante das notificações de acidentes por animais peçonhentos e da falta de pesquisas epidemiológicas que analisem a ocorrência dos agravos de acidentes com animais peçonhentos registrados na região serrana de Santa Catarina, torna-se relevante um estudo local sobre a incidência dos mesmos para que se conheça a frequência, tipo e a gravidade dessas intercorrências, contribuindo para a melhoria no atendimento à população, com a intenção de controlar e prevenir novos casos.

Portando, o objetivo do estudo consiste em descrever o perfil das notificações dos acidentes causados por animais peçonhentos e sua associação com fatores meteorológicos (temperatura do ar e precipitação) no município de Lages, Santa Catarina, para o período de 2011 a 2017.

\section{MATERIAL E MÉTODOS}

\section{Área de estudo}

O município de Lages está situado na região sul do Brasil, fazendo parte da mesorregião política e região geográfica serrana do estado de Santa Catarina (Figura 1). Com aproximadamente 2561 $\mathrm{km}^{2}$ de extensão, possui população de cerca de 158 mil habitantes, sendo que, destes, 98\% residem na área urbana e $2 \%$ na área rural (IBGE, 2018).

Segundo a classificação proposta por Köppen o clima da região é classificado como Cfb, ou seja, temperado, constantemente úmido, sem estação seca, com verões amenos (ALVARES et al., 2014). A temperatura média anual do ar varia entre $11^{\circ} \mathrm{C}$ e $21^{\circ} \mathrm{C}$, com máxima nos meses de janeiro e fevereiro e mínimas em junho. A precipitação anual média corresponde a 1600 $\mathrm{mm}$ (Figura 2), já a umidade relativa média anual varia entre $71 \%$ e $83 \%$ (PANDOLFO et al., 2012). 
Figura 1 - Mapa de localização do município de Lages

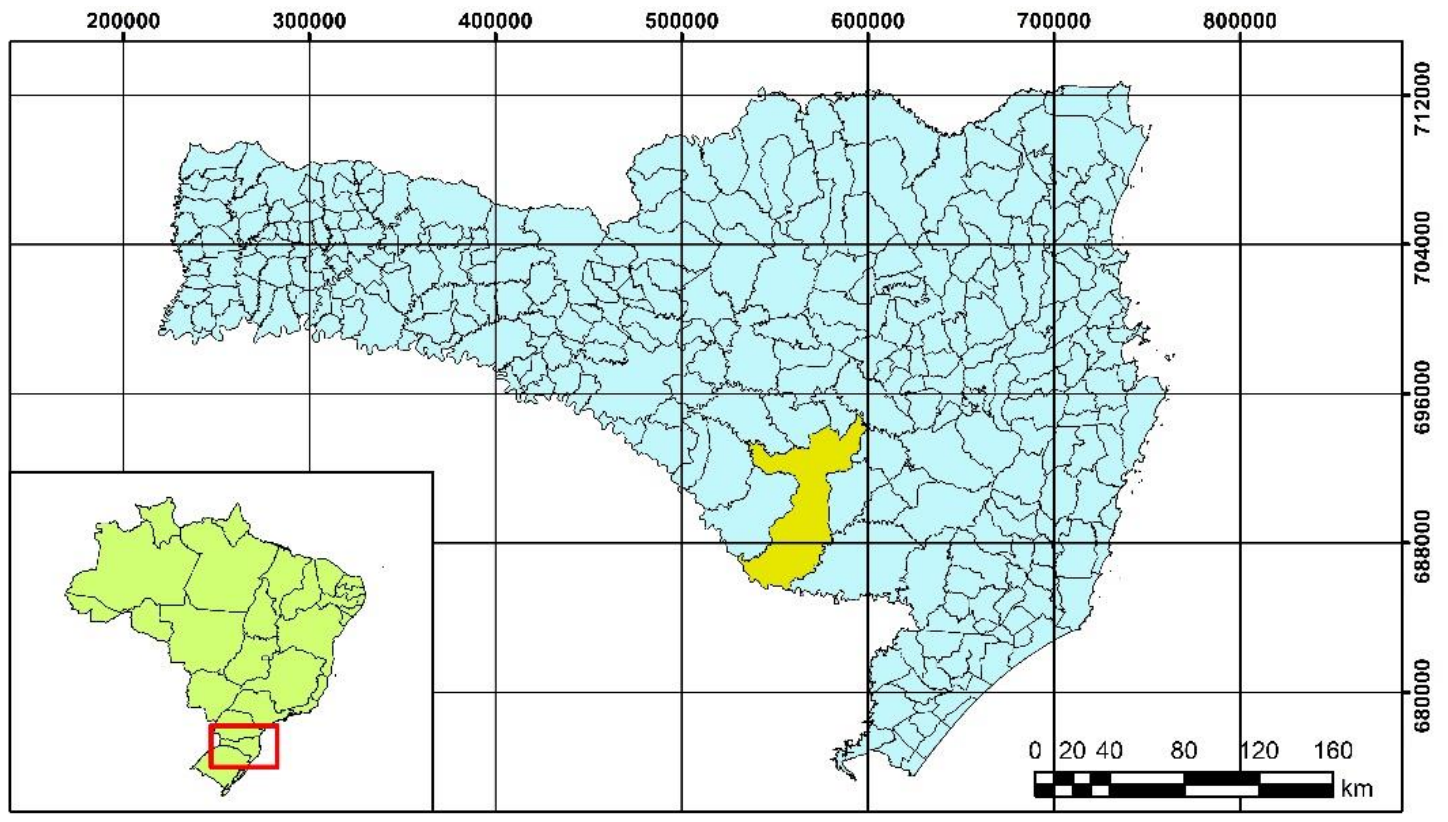

\begin{tabular}{|l|r|}
\hline Convenções Cartográficas \\
3 Estado de Santa Catarina & Sistema de Referência SIRGAS 2000 Zona 22S \\
Sistema de Projeção UTM \\
\hline
\end{tabular}

Fonte: autores, 2018.

Figura 2 - Climograma do município de Lages - SC

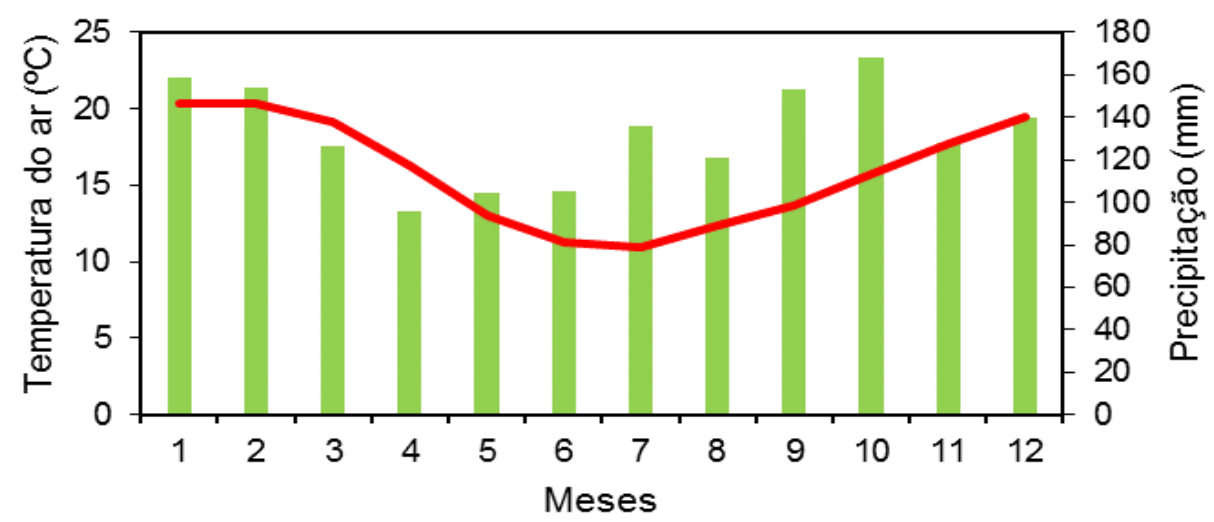

Precipitação Temperatura

Fonte: autores, 2018. 


\section{Coleta e análise de dados}

Para se obter os prováveis estímulos dos acidentes por animais peçonhentos foram considerados na pesquisa variáveis meteorológicas, sendo estas correspondentes a precipitação e temperatura do ar para o município de Lages.

As informações relativas aos números de notificações de acidentes por animais peçonhentos no período de estudo foram solicitadas por endereço eletrônico. Sendo assim, foram fornecidos os indicadores compulsórios do Sistema de Informação de Agravos de Notificação (SINAN), disponibilizados pela Vigilância Epidemiológica da Secretaria Municipal do município de Lages para os anos de 2011 a 2017.

Com relação ao número de notificações registradas para cada espécie de animal peçonhento, este foi obtido pelo Centro de Informação e Assistência Toxicológica de Santa Catarina (CIATox/SC), para o período de 2011 a 2017.

Os dados relacionados à precipitação e temperatura do ar para o período de interesse foram fornecidos pela Empresa de Pesquisa Agropecuária e Extensão Rural de Santa Catarina (EPAGRI/CIRAM). A partir destes, foi possível calcular no software Excel a temperatura média do ar diária e mensal e a precipitação total diária e mensal para cada ano de estudo a fim de se realizar a comparação com o número de notificações de acidentes por animais peçonhentos.

Com o auxílio do software Excel os casos de acidentes de animais peçonhentos foram organizados e referenciados em seus respectivos anos e meses de ocorrência, posteriormente utilizou-se o software estatístico SISVAR para a realização do teste da normalidade de Shapiro-Wlik.

Após o teste apontar a normalidade das amostras, foi possível efetuar o cálculo do coeficiente de correlação de Pearson. Para tanto, utilizou-se como variável independente os dados meteorológicos e como variável dependente os indicadores epidemiológicos.

O coeficiente de correlação de Pearson ( $r$ ) mede o grau da correlação linear entre duas variáveis quantitativas, sendo um índice adimensional com valores situados ente $-1,0$ e 1,0. Por existirem inúmeras condições que influenciam nessas variáveis, além do erro embutido, dificilmente as amostras apresentam uma correlação perfeita (SANTOS; FILHO, 2014).

\section{RESULTADOS E DISCUSSÃO}

Para o município de Lages pode-se observar que a maior causa dos acidentes notificados para os anos de estudo foi ocasionada por aranhas $(82 \%)$, seguido por escorpiões $(10 \%)$, serpentes $(6 \%)$, lagartas $(0,3 \%)$, abelhas $(0,1 \%)$ e outros animais $(1,6 \%)$, como formigas, vespas e besouros (Tabela 1$)$.

Tabela 1 - Notificação de acidentes por animais peçonhentos no município de Lages-SC entre 2011 e 2017

\begin{tabular}{ccccccc|c}
\hline Ano & Abelhas & Aranhas & Escorpiões & Lagartas & Serpentes & Outros & Total \\
\hline 2011 & 0 & 255 & 29 & 1 & 13 & 8 & $\mathbf{3 0 6}$ \\
2012 & 1 & 185 & 22 & 1 & 10 & 0 & $\mathbf{2 1 9}$ \\
2013 & 0 & 143 & 14 & 0 & 15 & 5 & $\mathbf{1 7 7}$ \\
2014 & 0 & 79 & 4 & 1 & 6 & 0 & $\mathbf{9 0}$ \\
2015 & 0 & 54 & 18 & 0 & 8 & 1 & $\mathbf{8 1}$ \\
2016 & 0 & 71 & 14 & 1 & 18 & 4 & $\mathbf{1 0 8}$ \\
2017 & 8 & 88 & 18 & 3 & 10 & - & $\mathbf{1 2 7}$ \\
\hline Total & $\mathbf{9}$ & $\mathbf{8 7 5}$ & $\mathbf{1 1 9}$ & $\mathbf{7}$ & $\mathbf{8 0}$ & $\mathbf{1 8}$ & \\
\hline
\end{tabular}

Fonte: SINAN, 2018. 
O número de casos anuais de acidentes por animais peçonhentos no município de Lages é superior a muitos municípios da região oeste de Santa Catarina (BUSATO et al., 2014). Contudo, este fato pode estar ligado ao número de habitantes, uma vez que se espera que onde a população é maior, há mais pessoas expostas a acidentes. Além disso, ressalta-se que o principal agente causador de acidentes, as aranhas, estão ocasionando acidentes também em área urbana.

De acordo com dados do SINAN (BRASIL, 2018) de 2011 a 2016 foram computados 53.397 acidentes envolvendo animais peçonhentos no estado de Santa Catarina, destes $29.499(65 \%)$ foram ocasionados por aranhas, $4.127(9 \%)$ por abelhas, $3.656(8 \%)$ por serpentes, $2.293(5 \%)$ por lagartas, $1.146(2,5 \%)$ por escorpiões, $2.718(5 \%)$ por outros animais e 2.107 notificações em que não foi possível realizar a identificação do animal causador da ocorrência do acidente (Figura 3).

Figura 3 - Número de acidentes com animais peçonhentos ocorridos no período de 2011 a 2016, no estado de Santa Catarina

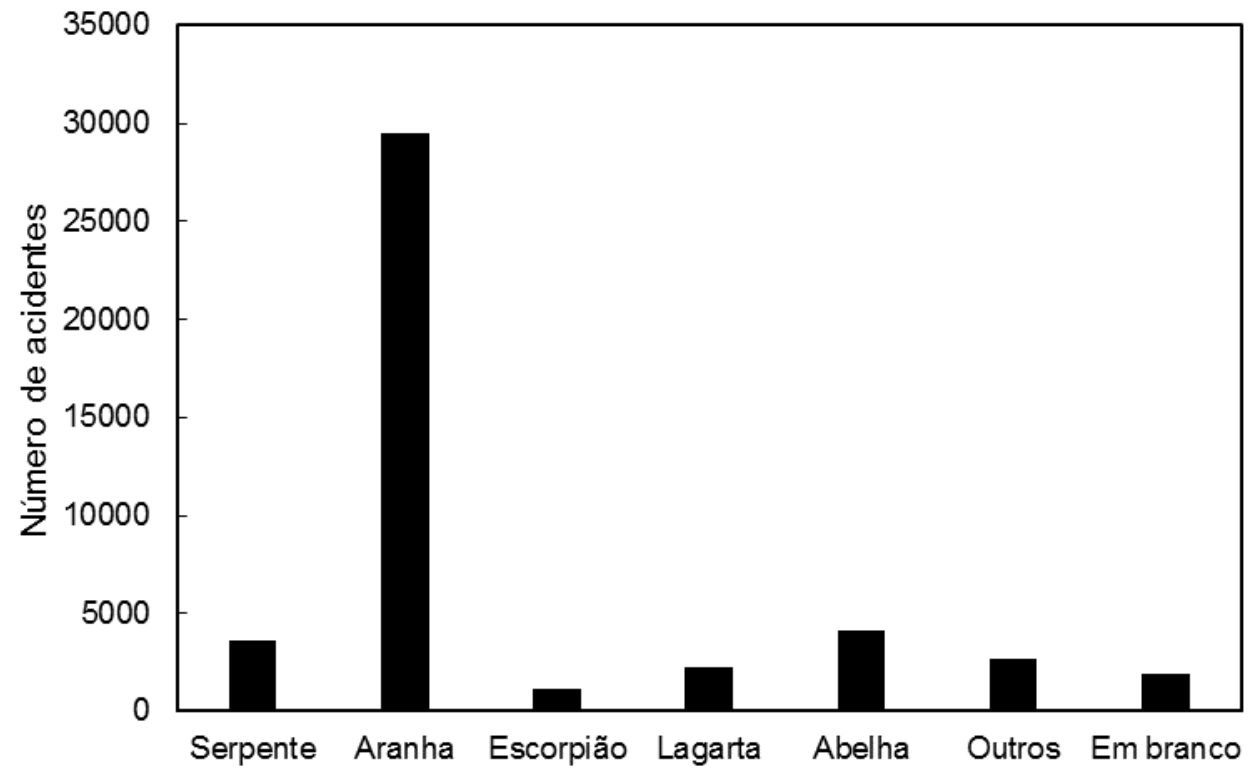

Fonte: SINAN, 2018.

Nota-se que o período com maior número de notificações de acidentes por animais peçonhentos corresponde aos anos de 2011 a 2013, coincidindo com os dados registrados para o município de Lages. Contudo, estes valores podem ser ainda maiores, em consequência da subnotificação, ou seja, de serem registrados números de acidentes inferiores aos reais e a omissão de casos, tanto por parte da população que deixa de procurar atendimento médico, quanto pelos órgãos responsáveis pelo registro de informações, havendo necessidade de melhorias no que se refere aos registros de notificações (GAMBORGl et al., 2012; JUNKES; MAZON, 2013).

Os acidentes por animais peçonhentos e suas respectivas frequências de ocorrência variam de acordo com cada região. No Paraná por exemplo, tem-se um maior número de acidentes ofídicos $(35,2 \%)$, seguido por aranhas $(28,2 \%)$ e por escorpiões $(11,6 \%)$, acidentes provocados por abelhas, lagartas e insetos não identificados variam de 6,7 a 7,3\% (MESCHIAL et al., 2013).

Ressalta-se que o risco de acidente por tais animais na zona rural se sobressai ao da zona urbana, em razão do trabalho dos indivíduos na agricultura que em muitos casos não utilizam equipamentos de proteção individual, contribuindo para uma maior exposição homem-animal (ROCHA et al., 2010; SELEGUIM et al., 2011). 
Apesar de serem registradas apenas nove ocorrências para o município de Lages entre 2011 a 2017, as abelhas são responsáveis pela segunda maior incidência de acidentes no estado de Santa Catarina para o mesmo período. Fato que pode estar atrelado à falta de procura médica pela população lageana em função do caso ser considerado como leve, apenas com sintomas locais, o que faz com que o número de notificações registradas seja inferior ao real (GAMBORGI et al., 2012).

As abelhas provocam na maioria dos casos apenas reações sutis nas vítimas, porém em certos casos, o indivíduo pode vir a desenvolver manifestações alérgicas e tóxicas a depender no local da picada, número de ferroadas, as características e o passado alérgico do indivíduo atingido (MINISTÉRIO DA SAÚDE, 2011).

Os gêneros predominantes de aranha e escorpião associados às notificações em Lages foram Loxosceles sp. e Tityus sp., respectivamente. Só no ano de 2017 foram registrados quarenta e três acidentes por Loxosceles sp. e dez por Tityus sp., sendo este ano superior no registro de acidentes quando comparado aos anos de 2014, 2015 e 2016 (CIATox/SC, 2019).

A Organização Mundial da Saúde (OMS) considera quatro gêneros principais de aranhas que apresentamimportância médica, Latrodectus (viúva-negra), Loxosceles (aranha marrom), Phoneutria (aranha armadeira) e Atrax (aranha-teia-de-funil). No Brasil, as aranhas de relevância médica pertencem aos três primeiros gêneros, sendo que os acidentes ocasionados por aranha Loxosceles correspondem aos mais frequentes nas regiões Sul e Sudeste do país (BUSATO et al., 2014). O mesmo se percebe para o município de Lages, em que as aranhas Loxosceles sp. são responsáveis pelo maior número de registros com relação a acidentes notificados (CIATox/SC, 2019).

No Brasil, das 160 espécies de escorpiões, as responsáveis pelos acidentes graves pertencem ao gênero Tityus, sendo a Tityus serrulatus (LUTZ; MELLO, 1992), Tityus bahiensis (PERTY, 1833), Tityus stigmurus (THORELL, 1876) e T.trivittatus (KRAEPELIN, 1898) as principais espécies (BRASIL, 2019). De acordo com Reckziegel, Junior (2014) entre 2000 e 2010 foram notificados 359.427 acidentes escorpiônicos no Brasil, dos quais 561 evoluíram para óbito. As taxas médias anuais de incidência e mortalidade, para cada 100 mil habitantes, foram de 17,7 e 0,028, respectivamente; sendo de $0,16 \%$ a taxa média anual de letalidade no Brasil.

Embora tenha havido uma baixa frequência nas notificações de acidentes por escorpiões, sendo esta equivalente a apenas $2 \%$ do total para o estado de Santa Catarina, se tratando do município de Lages o mesmo foi significativo (11\%) para o período correspondente aos anos de 2011 a 2017. Deve-se destacar, ainda, que os acidentes provocados por escorpiões podem evoluir para óbitos.

De acordo com Quadros et al. (2014) considerando o período de 2000 a 2010, dos doze municípios da região serrana de Santa Catarina, constatou-se que Lages possuia a segunda maior ocorrência de acidentes por escorpião, sendo este equivalente a $27,2 \%$. Além disso, pode-se notar um aumento no número de notificações para os últimos quatro anos avaliados. Os acidentes devido ao contato direto com lagartas vêm ganhando destaque entre os pesquisadores da área da saúde pública principalmente pelo aumento considerável de ocorrências a partir da década de 1990 (GAMBORGI et al., 2012). Os casos ocorrem frequentemente no verão e no outono, em razão de serem os períodos mais quentes do ano, estabelecendo relação com o ciclo biológico desses animais (MINISTÉRIO DA SAÚDE, 2011). O lepidóptero Lonomia sp., concentra os maiores índices de notificações na região sul do Brasil e apesar de já se ter um tratamento específico que contribui para um menor número de complicações e óbitos, os acidentes continuam a acontecer (AZEVEDO, 2011).

O Brasil apresenta uma das mais ricas faunas de serpentes do planeta, sendo conhecidas 366 espécies de serpentes. Dessas, 15\% (55 espécies) são consideradas peçonhentas e responsáveis por cerca de 20 mil acidentes ofídicos anualmente no país (BERNARDE, 2011). Em Santa Catarina no ano de 2017 foram notificados 693 acidentes, correspondendo a $2,5 \%$ do total registrado no pais (SINAN, 2018).

Com relação ao gênero predominante de serpente associado às notificações no município de Lages, este corresponde a Bothrops sp. No ano de 2017 foram computados cinco acidentes envolvendo este gênero, sendo este ano superior no registro de acidentes quando comparado aos anos de $2014 \mathrm{e}$ 2015, que tiverem respectivamente dois e três casos notificados (CIATox/SC, 2019).

Em 2011 teve-se uma despesa superior a três milhões de reais com internações provocadas por acidentes de animais peçonhentos, tendo como gasto médio um valor de $R \$ 257,45$ reais para DOI:http://dx.doi.org/10.14393/Hygeia153146311 Hygeia 15 (31): 43 - 55, Março/2019 página 49 
cada internação, demonstrando o quão oneroso pode ser o gasto para o Sistema Único de Saúde (SUS) em razão desse tipo de ocorrência (BRASIL, 2018).

Pode-se notar que a incidência no número de casos de acidentes por animais peçonhentos nos meses de verão é superior aos demais, principalmente no mês de janeiro, enquanto que nos meses correspondentes ao período de inverno se tem uma redução na incidência (Figura 4).

Figura 4 - Média dos casos de acidentes por animais peçonhentos do município de Lages para os anos de 2011-2017

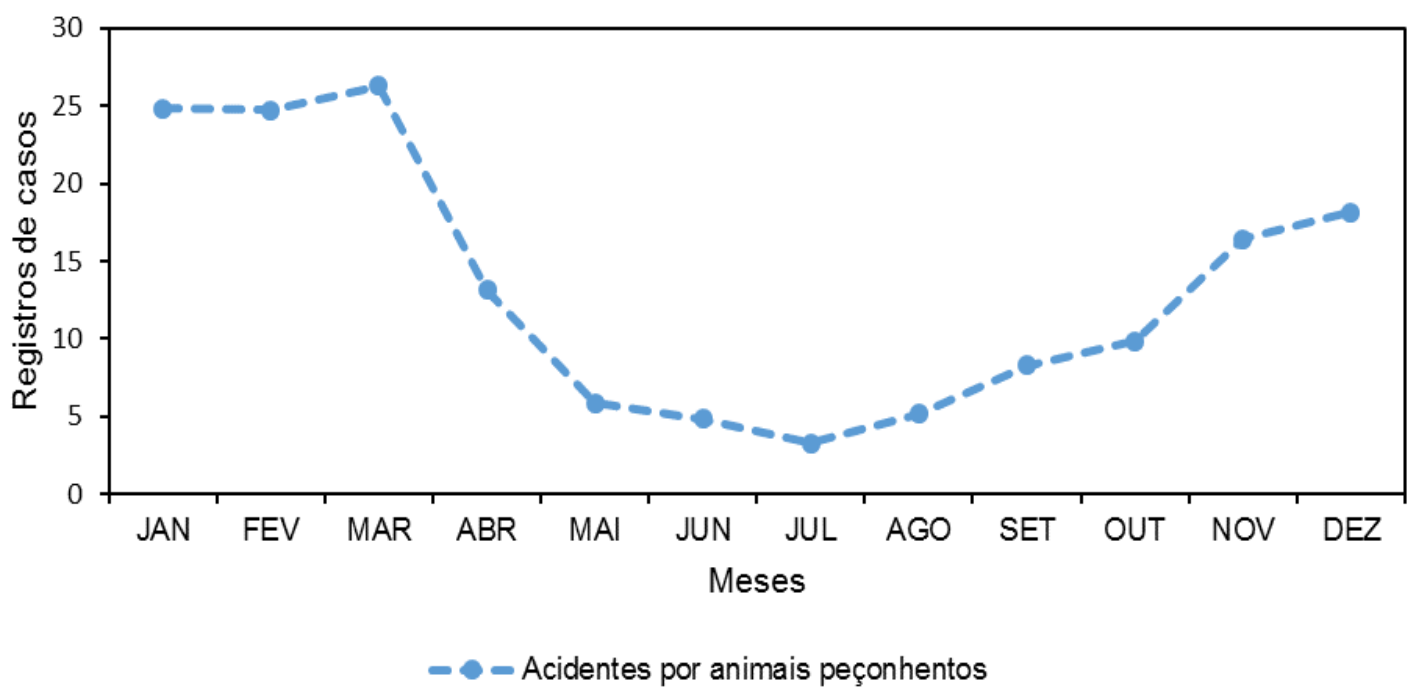

Fonte: autores, 2018.

A maior frequência de acidentes por animais peçonhentos se refere ao mês de janeiro, período no qual se tem registro de altas precipitações $(150 \mathrm{~mm})$ e temperatura do ar elevada. Oliveira; Costa, Sassi (2013) obtiveram em seu estudo que os meses mais chuvosos coincidem com o maior surgimento de animais peçonhentos, devido aos mesmos estarem em procura de abrigo. Além disso, o aumento na temperatura do ar torna os animais mais ativos, o que contribui para a ocorrência de acidentes (MINISTÉRIO DA SAÚDE, 2017).

Outro fator que favorece a maior concentração de casos entre dezembro e janeiro é o período de férias em que muitos indivíduos fazem a limpeza dentro de seus imóveis e terrenos, bem como, realizam atividades ao ar livre e acampamentos. Tais fatores favorecem a exposição de crianças e adultos a esses animais, provocando por consequência, maiores índices de acidentes neste período do ano (SELEGUIM et al., 2011).

A correlação das variáveis meteorológicas com as notificações dos acidentes, indica que o número de acidentes por animais peçonhentos demonstrou uma maior associação com a temperatura do ar do que com a precipitação, sendo o valor mais alto obtido para o ano de 2013 (Figura 5).

O valor do coeficiente de determinação de Pearson demonstra uma relação positiva moderada forte $(r=0,75)$, sendo este significativa considerando $5 \%$ de significância $(p=0,036)$, o que indica uma forte relação linear entre as notificações de acidentes por animais peçonhentos e a temperatura do ar. 
Figura 5 - Relação entre temperatura do ar e acidentes por animais peçonhentos para o município de Lages em 2013

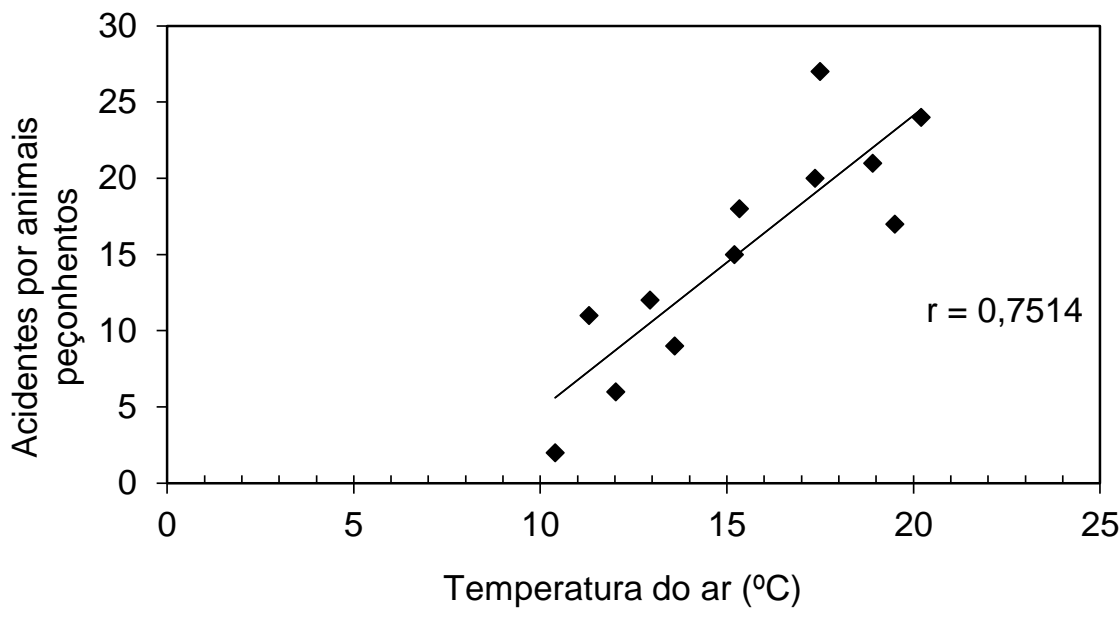

Fonte: autores, 2018.

Analisando a distribuição dos acidentes com as variações médias mensais de temperatura do ar pode-se verificar que nos meses correspondentes ao verão, em que a temperatura do ar encontrase elevada há uma maior incidência de casos registrados (Figura 6).

O mesmo fato foi evidenciado por Haas et al. (2013) e Zanella, Cechin (2009) uma vez que a maior manifestação de acidentes ocorreu nos meses de janeiro a março e novembro a dezembro, comprovando que o período mais ativo do ano coincide com os meses em que a temperatura é mais elevada.

Figura 6 - Disposição de acidentes por animais peçonhentos com relação a temperatura do ar para o município de Lages entre os anos de 2011 a 2017

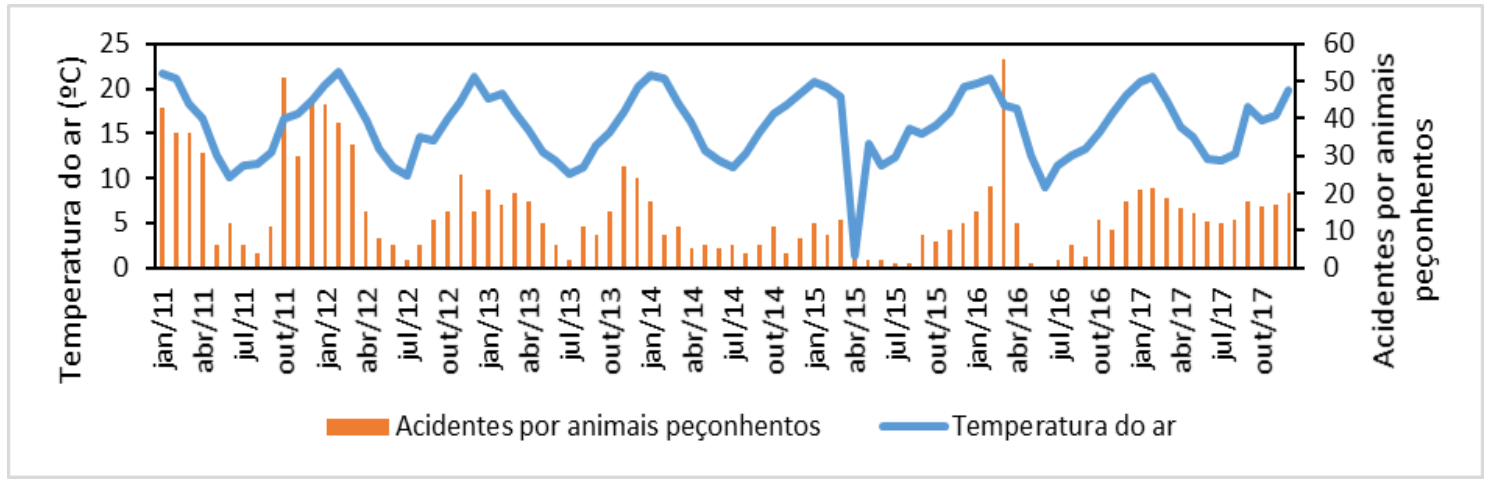

Fonte: autores, 2018.

No Brasil, fatores climáticos, como a temperatura do ar e a precipitação, além de fatores sociodemográficos podem favorecer a proliferação de animais peçonhentos, bem como contribuir para a associação do habitat desses animais às atividades humanas, ocasionando acidentes (SANTANA; BARROS; SUCHARA, 2016). Embora se tenha alguns estudos publicados sobre os 
acidentes envolvendo animais peçonhentos, nota-se uma carência de pesquisas que busquem relacionar as notificações com as condições meteorológicas no estado de Santa Catarina e, principalmente, na serra catarinense.

No estado do Rio Grande do Sul as notificações de acidentes por aranhas apontam para uma sazonalidade nos meses de outubro a abril, seguindo os padrões conhecidos da literatura, em que se constata que os acidentes estão relacionados com o período de acasalamento e maior atividade (locomoção principalmente) das aranhas nos meses mais quentes do ano (CHAGAS; D'AGOSTINE; BETRAME, 2010).

Um estudo desenvolvido por Gamborgi et al. (2012) na região oeste de Santa Catarina aponta que os aspectos climáticos relacionados à temperatura e à elevação pluviométrica com precipitação são fatores determinantes para a proliferação de larvas da lagarta da espécie Lonomia sp. em que os meses de dezembro a abril, cuja variação da temperatura foi de $21^{\circ} \mathrm{C}$ a $34,6^{\circ} \mathrm{C}$, correspondem a $83,8 \%$ do total de notificações de acidentes por esse animal.

D'agostini; Chagas; Beltrame, (2011) constataram uma sazonalidade quanto à incidência de acidentes por serpentes em Concordia/SC, nos meses mais quentes, sendo este referente ao período de novembro a março, em que foram registrados $79,94 \%$ do total de casos, com destaque para o mês de janeiro com maior percentual de acidentes (19,24\%).

De acordo com Nicoleti (2010), as serpentes apresentam maior atividade em estações quentes, o que as torna mais visíveis e ocasiona aumento no número de acidentes. Nos meses frios, estes animais apresentam-se na fase imatura de desenvolvimento, ocasionando na diminuição de sua movimentação, além de passarem a maior parte do tempo em abrigos.

Investigando as internações hospitalares de vítimas de acidentes por animais peçonhentos no Paraná, Meschial et al. (2013) verificaram que a maioria das internações ocorreu nos meses do verão $(39,0 \%)$ e da primavera $(27,0 \%)$, representando $66 \%$ dos casos.

Tal relação também foi percebida no presente estudo, o qual mostra graficamente a quantidade de notificações de acidentes por animais peçonhentos em relação à temperatura do ar média ao longo dos meses do ano. Estes animais, em sua maioria, apresentam comportamento ativo em meses quentes, os quais estão ligados a época de alimentação e acasalamento. Em razão disso, ficam expostos, adentram edificações, são vistos em ambiente laborais e locais públicos e, por sentirem-se ameaçados pelos humanos, acabam ocorrendo os acidentes (MINISTÉRIO DA SAÚDE, 2017).

Logo, tem-se indícios de que a sazonalidade está intimamente ligada aos acidentes com animais peçonhentos, pois é verificada uma quantidade de casos superiores em período de maior temperatura (BARBOSA, 2015). Além disso, o desmatamento e a atividade agropecuária, como o plantio, tratos culturais e colheita de safra agrícola, atuam como potencializadores dos acidentes, em razão da mudança do meio natural dos animais e da grande movimentação de pessoas e máquinas (OLIVEIRA; COSTA; SASSI, 2013).

Os casos de acidentes por animais peçonhentos representam um problema de saúde pública do país. Modificações no ambiente natural em decorrência da urbanização atrelado a condições sanitárias insatisfatórias e a falta de conhecimento da população sobre as práticas de prevenção podem favorecer o aparecimento destes animais em residências, expondo indivíduos ao risco de intoxicação e em casos mais graves, ao óbito (BUSATO et al., 2014).

\section{CONCLUSÃO}

O comportamento de doenças e sua intensificação devido a condições meteorológicas ainda é um assunto pouco estudado no país. Conhecer o perfil das notificações dos acidentes por animais peçonhentos e sua associação com fatores meteorológicos (temperatura do ar e precipitação) e suas possíveis causas torna-se uma medida importante para o direcionamento de ações mitigatórias e informativas para as populações.

O estudo permitiu evidenciar o agente responsável pela maior parte dos acidentes, tanto no estado de Santa Catarina, quanto no município de Lages, são as aranhas, em que as notificações se 
sobressaem aos de abelha, escorpiões, lagartas, serpentes e outros animais peçonhentos, apontando para uma maior vulnerabilidade da população para o araneísmo.

No município de Lages observou-se que a ocorrência de acidentes por animais peçonhentos apresenta relação com o aumento de temperatura do ar, para o período entre 2011 e 2017, em que o número de registros de notificações sofre um acréscimo nos meses correspondentes ao período de verão.

Dessa forma, campanhas informativas sobre o risco de acidentes por esses animais, em especial nos meses entre novembro e março se faz importante para que a população seja alertada e possa tomar maiores precauções.

Além disso, nota-se a relevância em se traçar estratégias de busca ativa de casos de acidentes por animais peçonhentos, além da promoção de atividades sensibilizadoras para o efetivo registro nas estatísticas oficiais do Ministério da Saúde, evitando, dessa forma, casos de subnotificações ou omissões, os quais interferem na computação real dos dados.

\section{REFERÊNCIAS}

ALVARES, C. A. et al. Köppen's climate classification map for Brazil. Meteorologische Zeitschrift, v. 22, n. 6, p. 711-728, January 2014. Disponível em: <

http://www.lerf.eco.br/img/publicacoes/Alvares_etal_2014.pdf>. Acesso em: 10 fev. 2019. https://doi.org/10.1127/0941-2948/2013/0507

AZEVEDO, T. S. Distribuição biogeográfica da ocorrência de acidentes provocados por lagartas do gênero Lonomia, no Brasil, no período de 2000 a 2007. Hygeia. v.7. n.13. p.124- 131, 7 nov. 2011. Disponível em: < http://www.seer.ufu.br/index.php/hygeia/article/view/17041/9396>. Acesso em: 7 dez. 2018.

BARBOSA, I. R. Aspectos clínicos e epidemiológicos dos acidentes provocados por animais peçonhentos no estado do Rio Grande do Norte. Revista Ciência Plural, v.1, n.2, p.2-13, 7 fev. 2015. Disponível em: <https://periodicos.ufrn.br/rcp/article/view/8578/6179>. Acesso em: 14 jan. 2019.

BERALDO, H. S. et al. Acidentes com animais peçonhentos notificados em um hospital escola. Revista Varia Scientia, v.3, n.2, p. 194-200, jul. 2017. Disponível em: <http://erevista.unioeste.br/index.php/variasaude/article/view/17691/12253>. Acesso em: 10 fev. 2019.

BERNARDE, P. S. Mudanças na Classificação de Serpentes Peçonhentas Brasileiras e suas implicações na Literatura Médica. Gazeta Médica da Bahia, v. 81, n. 1, p. 55-63, 3 jan. 2011. Disponível em: <http://www.gmbahia.ufba.br/index.php/gmbahia/article/viewFile/1141/1076>. Acesso em: 14 jan. 2019.

BRASIL. Ministério da Saúde. Acidente por animais peçonhentos - Notificações registradas no Sistema de Informação de Agravos de Notificação - SINAN Net. 2018. Disponível em: < http://tabnet.datasus.gov.br/cgi/deftohtm.exe?sinannet/animaisp/bases/animaisbrnet.def $>$. Acesso em: 5 dez. 2018.

BRASIL. Secretaria Da Saúde do Estado do Paraná. Escorpianismo (acidentes). Disponível em: < http://www.saude.pr.gov.br/modules/conteudo/print.php?conteudo=1453>. Acesso em: 28 jan. 2019.

BUSATO, M. A. et al. Acidente por animais peçonhentos do oeste do Estado de Santa Catarina, Brasil. Hygeia, Uberlândia, v.10, n.3, p.190-206, 23 mai. 2014. Disponível em: < http://www.seer.ufu.br/index.php/hygeia/article/view/23755/14827>. Acesso em: 10 dez. 2018.

Centro de Informação e Assistência Toxicológica de Santa Catarina (CIATox/SC). 2019. Estatística anual de Casos de Intoxicação e Envenenamento. Florianópolis. 2019.

CHAGAS, F. B.; D'AGOSTINE, F. M; BETRAME, V. Aspectos epidemiológicos dos acidentes por aranhas no Estado do Rio Grande do Sul, Brasil. Evidência. v.10, n.1, p.121-130, jan. 2010. Disponível em:

<https://www.researchgate.net/publication/299341548_Aspectos_epidemiologicos_dos_acidentes_por _aranhas_no_Estado_do_Rio_Grande_do_Sul_Brasil>. Acesso em: 5 dez. 2018. 
D'AGOSTINI, F. M.; CHAGAS, F. B.; BELTRAME, V. Epidemiologia dos acidentes por serpentes no município de Concórdia, SC no período de 2007 a 2010. Evidência, Joaçaba v. 11 n. 1, p. 51-60, jan. 2011. Disponível em: <

https://www.researchgate.net/publication/277108939_Epidemiologia_dos_acidentes_por_serpentes_n o_municipio_de_Concordia_SC_no_periodo_de_2007_a_2010 >. Acesso em: 5 dez. 2018.

Diretoria De Vigilância Epidemiológica - DIVE. Boletim barriga verde - acidentes por animais peçonhentos. Informativo Epidemiológico. Ano XV - Edição Especial. 2018. Disponível em: < http://www.dive.sc.gov.br/conteudos/boletim2018/BoletimBarrigaVerdeAnimais/BV_Peconhentos_final .pdf>. Acesso em: 28 jan. 2019.

GAMBORGI, G. P. et al. Influência dos fatores abióticos sobre casos de acidentes provocados por Lonomia obliqua. Hygeia, v.8, n.14, p. 201 - 208, 1 jan. 2012. Disponível em: < https://www.unochapeco.edu.br/static/data/portal/downloads/2710.pdf>. Acesso em: 7 jan. 2019.

HASS, J. et al. Acidentes com aranhas do gênero Loxosceles sp. em Laranjeiras do Sul PR. Semina: Ciências Biológicas e da Saúde, Londrina, v. 34, n. 1, p. 15-22, jan. 2013. Disponível em: < http://www.uel.br/revistas/uel/index.php/seminabio/article/view/10355/13732>. Acesso em: 7 jan. 2019. https://doi.org/10.5433/1679-0367.2013v34n1p15

IBGE - Instituto Brasileiro de Geografia a Estatística. População estimada: IBGE. Diretoria de Pesquisas, Coordenação de População e Indicadores Sociais, Estimativas da população residente com data de referência $1^{\circ}$ de julho de 2018. Disponível em: < https://cidades.ibge.gov.br/brasil/sc/lages/panorama>. Acesso em: 1 fev. 2019.

JUNKES, C. H. G.; MAZON, L. M. Prevalência dos acidentes por Tityus costatus e Loxosceles sp. no município de Rio Negrinho/SC e ações profiláticas adotadas pela população. Saúde Meio Ambient. v. 2, n. 1, p. 33-43, 20 ago. 2013. Disponível em:

<http://www.periodicos.unc.br/index.php/sma/article/view/322>. Acesso em: 20 jan. 2019.

https://doi.org/10.24302/sma.v2i1.322

LEOBAS, G. F.; FEITOSA, S. B.; SEIBERT, C. S. Acidentes por animais peçonhentos no estado do Tocantins: Aspectos clínico- epidemiológicos. Revista Interdisciplinar da Universidade Federal do Tocantins. v. 2 n.2. p.269-282, mai. 2016. Disponível em: < https://www.researchgate.net/publication/305452336_Acidentes_por_animais_peconhentos_no_Estad o_do_Tocantins_aspectos_clinico-epidemiologicos>. Acesso em: 15 dez. 2018. https://doi.org/10.20873/uft.2359-3652.2016v2n2p269

MESCHIAL, W. C. et al. Internações hospitalares de vítimas de acidentes por animais peçonhentos. Rev Rene. v. 14, n.2, p.311-319, abr. 2013. Disponível em: <

https://www.researchgate.net/publication/277077501_Internacoes_hospitalares_de_vitimas_de_acide ntes_por_animais_peconhentos>. Acesso em: $15 \mathrm{dez} .2018$.

Ministério da Saúde (BR). Fundação Nacional de Saúde. Manual de diagnóstico e tratamento de acidentes por animais peçonhentos. $2^{\mathrm{a}}$ ed. Brasília: Ministério da Saúde; 2011. Disponível em: < http://bvsms.saude.gov.br/bvs/publicacoes/funasa/manu_peconhentos.pdf $>$. Acesso em: 3 dez. 2018.

Ministério da Saúde (BR). Promoção a Saúde. Acidentes com animais peçonhentos, 2017. Disponível em: <http://portalms.saude.gov.br/saude-de-a-z/acidentes-por-animais-peconhentos>. Acesso em: 5 dez. 2018.

NICOLETI, A. F. Comparação dos acidentes causados por Bothropoides jararaca (Serpentes: Viperidae) com e sem envenenamento atendidos no Hospital Vital Brazil do Instituto Butantan. 2010. 128 f. Dissertação (Mestrado em Ciências) - Faculdade de Medicina da Universidade de São Paulo, São Paulo, 22 out. 2010. Disponível em: < http://www.teses.usp.br/teses/disponiveis/5/5134/tde-25112010-102912/pt-br.php>. Acesso em: 20 jan. 2019.

OLIVEIRA, H. F. A.; COSTA, C. F.; SASSI, R. Relatos de acidentes por animais peçonhentos e medicina popular em agricultores de Cuité, região do Curimataú, Paraíba,

Brasil. Rev Bras Epidemiol. v.16, n.3, p.633-43, nov. 2013. Disponível em: < http://dx.doi.org/10.1590/S1415-790X2013000300008. . . Acesso em: 26 nov. 2018. 
PANDOLFO, C. et al. Atlas climatológico do Estado de Santa Catarina. Florianópolis: Epagri, 2012. Disponivel em: <

http://www.ciram.epagri.sc.gov.br/ciram_arquivos/arquivos/atlasClimatologico/atlasClimatologico.pdf>. Acesso em: 2 dez. 2018.

QUADROS, R. M. et al. Acidentes escorpiônicos notificados pelo SINAN na região serrana de Santa Catarina, Brasil, 2000-2010. REB, v.7, n.1, p.96-108, 2014. Disponível em: < https://revistas.pucsp.br/reb/article/view/17065/14687>. Acesso em: 15 jan. 2019.

RECKZIEGEI, G. C.; JUNIOR, V. L. P. Análise do escorpionismo no Brasil no período de 2000 a 2010. Rev Pan-Amaz Saúde, v.5, n.1, p.67-68, mar. 2014. Disponível em: < http://scielo.iec.gov.br/scielo.php?script=sci_arttext\&pid=S2176-62232014000100008>. Acesso em: 15 jan. 2019. https://doi.org/10.5123/S2176-62232014000100008

ROCHA, L. R. R. et al. Perfil de adoecimento de trabalhadores rurais no interior do estado de São Paulo. Ciênc Cuid Saúde. v. 9, n. 4, p.713-720, out. 2010. Disponível em: < http://periodicos.uem.br/ojs/index.php/CiencCuidSaude/article/view/13818/7189>. Acesso em: 15 dez. 2018. https://doi.org/10.4025/cienccuidsaude.v9i4.13818

SANTANA, V. T. P.; BARROS, J. O.; SUCHARA, E. A. Aspectos clínicos e epidemiológicos relacionados a acidentes com animais peçonhentos. Revista de Ciências Médicas e Biológicas, v.14, n.2, p.153-159, ago. 2016. Disponível em: <https://portalseer.ufba.br/index.php/cmbio/article/view/13079/10834>. Acesso em: 12 dez. 2018. https://doi.org/10.9771/cmbio.v14i2.13079

SANTOS, C. F.; TORNQUIST, C. C.; MARIMON, M. P. C. Indústria das enchentes: Impasses e desafios dos desastres socioambientais no Vale do Itajaí. Geosul, v.29, n.57, jun. 2014. Disponível em: https://periodicos.ufsc.br/index.php/geosul/article/view/2177-5230.2014v29n57p197/27989>. Acesso em: $21 \mathrm{dez}$. 2018. https://doi.org/10.5007/25740

SANTOS, D.; FILHO, M. R. T. Estudo sobre a influência de variáveis meteorológicas em internações hospitalares em Maceió-AL, durante o período 1998 a 2006. Revista Brasileira de Meteorologia, v.29, n.3, p.457- 467, 2014. Disponível em: < http://www.scielo.br/pdf/rbmet/v29n3/a13v29n3.pdf >. Acesso em: 12 dez. 2018. https://doi.org/10.1590/0102-778620110324

SELEGHIM M. R. et al. Acidentes por serpentes e utilização de soroterapia antipeçonhenta. Arq Ciênc Saúde Unipar. v. 15, n.2, p.141-148, ago. 2011. Disponível em: < http://bases.bireme.br/cgibin/wxislind.exe/iah/online/?IsisScript=iah/iah.xis\&src=google\&base=LILACS\&lang=p\&nextAction=Ink \&exprSearch=621314\&indexSearch=ID $>$. Acesso em: 10 dez. 2018.

SOUZA, R. F.; NASCIMENTO, S. L. Doenças e agravos no contexto das grandes inundações graduais no estado do Amazonas - Brasil. Hygeia. v. 13, n.26, p. 139-147, 7 nov. 2017. Disponível em: <http://www.seer.ufu.br/index.php/hygeia/article/view/39732>. Acesso em: 12 dez. 2018. https://doi.org/10.14393/Hygeia132611

ZANELLA, N.; CECHIN, S. Z. Influência dos fatores abióticos e da disponibilidade de presas sobre comunidade de serpentes do Planalto Médio do Rio Grande do Sul. Iheringia, Sér. Zool., Porto Alegre, v.99, n.1, p.111-114, 3ํㅡar. 2009. Disponível em: < http://www.scielo.br/pdf/isz/v99n1/v99n1a16.pdf>. Acesso em: 11 dez. 2019. https://doi.org/10.1590/S0073-47212009000100016 